\title{
Schizophrenia Long-Acting Injectable Antipsychotic Initiation Index: A Clinician Rated Instrument for Improving Treatment in Schizophrenia
}

Petru Ifteni ( $\square$ petru.ifteni@unitbv.ro)

Transilvania University of Brasov

Andreea Teodorescu

Transilvania University of Brasov

\section{Research Article}

Keywords: schizophrenia, antipsychotic, treatment, relapse, outcome, long-acting injectable

Posted Date: April 22nd, 2021

DOl: https://doi.org/10.21203/rs.3.rs-437463/v1

License: (c) (1) This work is licensed under a Creative Commons Attribution 4.0 International License.

Read Full License 


\section{Abstract}

Background: Schizophrenia is a severe psychiatric condition with devastating consequences for the individual's functionality and leading to severe disability. Lack of insight and non-adherence to treatment remain the most important factors in the progression of the disease to chronicity.

Despite their proven effectiveness in preventing relapses, reducing morbidity and mortality, long acting injectable antipsychotics (LAls) are still underused. One of the causes invoked is the lack of guidelines or protocols for initiating LAls.

Objective: The aim of this article is to present Schizophrenia long-acting injectable antipsychotic initiation index (SLAII), a clinician-rated index that rates the important factors of the disorder across seven items: age, duration of illness, relapses, antipsychotic treatment response, family support, antipsychotic existing formulation and adherence.

Method: A retrospective study in which all patients with schizophrenia discharged on oral antipsychotics without LAls treatment lifetime were evaluated with SLAll for opportunity for LAls initiation.

Results: Of 225 consecutive patients, 144 patients (64\%) had a strong indication for initiating LAl and 76 (34\%) had moderate indication. 203 patients $(90.2 \%)$ had more than 2 relapses. The results of our research showed that 177 patients $(78.7 \%)$ received at discharge an oral antipsychotic that also had a long-acting formula.

Conclusion: This paper proposed an instrument designed to improve treatment in schizophrenia using a simple conceptual model which integrates important predictors of good or poor outcomes.

\section{Introduction}

Schizophrenia is a severe psychiatric condition with devastating consequences for the individual's functionality and leading to severe disability [1,2]. Lack of insight and non-adherence to treatment remain the most important factors in the progression of the disease to chronicity [3-5].

Despite their proven effectiveness in preventing relapses, reducing morbidity and mortality, LAls are still underused [6-8]. The main causes of low utilization are related to the patient (fear of needles, stigma, desire not to be under control, etc.) but also to the clinicians (costs, personal beliefs or lack of experience) $[9,10]$. One of the causes invoked by clinicians is the lack of guidelines or protocols for initiating LAls. Because of this, initiation with LAls is often delayed, or LAls are used in severe forms of the disease or even in cases considered treatment-resistant $[11,12]$.

The development of an instrument for psychiatrists to provide a quick orientation on the opportunity to initiate treatment with LAl could improve adherence and outcome in schizophrenia.

\section{Aims Of The Study}


This paper describes an instrument called Schizophrenia long-acting antipsychotic initiation index Schizophrenia Long-acting injectable antipsychotic Initiation Index), designed to improve initiation of LAls. This index is a conceptual model, based on the continuous work over the past 20 years for a better adherence and outcome in schizophrenia.

\section{Methods}

\subsection{Rationale for LAl initiation index}

There are no initiation guidelines or protocols but only indications and suggestions from experts $[13,14]$. Often psychiatrists consider that it is not yet the time, the patient could refuse LAl, the costs can be higher, the supervision must be more careful, thus delaying initiation.

The SLAll Index provided was developed by an experienced schizophrenia research group leading by Petru Ifteni, M.D., PhD, professor of psychiatry at Transilvania University of Brasov, Romania, Faculty of Medicine.

\subsection{Description of the index}

Schizophrenia long-acting injectable initiation index is a clinician-rated instrument that is scored using available clinical information for each of the seven domains. Each item is rated on a 3-point scale with 5 points, 3 points, and 1 point. Based on the patient's data, the clinician will choose one value (e.g. age between 18 and 25 will be scored with 5 points) for all seven items. The final score is the sum of all seven items. SLAll is presented in table 1.

Table 1. Schizophrenia long-acting injectable antipsychotic initiation index 


\begin{tabular}{|ll|}
\hline DOMAINS & Score \\
\hline I. Age & \\
\hline $18-25$ years & 5 points \\
\hline $26-35$ years & 3 points \\
\hline$>35$ years & 1 point \\
\hline & \\
\hline II. Duration of illness & \\
\hline $2-5$ years & 5 points \\
\hline $6-10$ years & 3 points \\
\hline$>10$ years & 1 point \\
\hline & \\
\hline III. Relapse & 3 points \\
\hline 3 or more relapses & \\
\hline 2 relapses & 5 points \\
\hline 1 relapse & 3 points \\
\hline & 1 point \\
\hline IV. Response to oral antipsychotic & \\
\hline good response/remission & \\
\hline partial response & \\
\hline poor response/treatment-resistant & \\
\hline & \\
\hline & \\
\hline & \\
\hline
\end{tabular}




\begin{tabular}{|lc|}
\hline both oral and LAI & 5 points \\
\hline only oral & 3 points \\
\hline clozapine & 1 point \\
\hline VII. Treatment adherence & \\
\hline non-adherence & 5 points \\
\hline partial adherence & 3 points \\
\hline good adherence & 1 point \\
\hline
\end{tabular}

(C) Petru Ifteni, M.D.

\subsection{Theoretical rationale for items}

The index items are derived from consideration of important elements involved in the outcome of schizophrenia: age, duration of illness, number of relapses, antipsychotic treatment response, family support and adherence.

\section{Age}

The patient's age is a key factor in subsequent evolution. Young patients may still have many neurocognitive resources for treatment response, remission and recovery [15]. Thus, for the age between 18 and 25 years we gave 5 points, for the age between 26 and 35 years we gave 3 points, and for those aged between 36 and 45 years, we gave 1 point.

\section{Duration of illness}

Studies show that neuropathological changes occur in the first years of the disease [16]. Thus, the first 2-5 years can be considered to have major importance for the patient. We rated with 5 points for patients with a disease duration between 2 and 5 years, 3 points for a duration between 6 and 10 years and 1 point for a disease duration over 10 years.

\section{Relapses}

Relapses and hospitalizations in the early years are a prognostic factor for the unfavorable evolution towards cognitive decline and chronicity $[17,18]$. Therefore, experts recommend the early initiation of LAl, after the first relapses caused by non-adherence. We rated with 5 points for at least 3 relapses, 3 points for 2 relapses and 1 point for 1 relapse.

\section{Response to oral antipsychotic}


Many young people with schizophrenia respond well to the first trials with antipsychotics, a significant percentage even get remission [19]. Individual responsiveness, the severity of pathology are criteria that influence the choice of antipsychotic and doses. The therapeutic response decreases significantly with the increasing number of relapses [20]. We rated 5 points for complete therapeutic response/remission, 3 points for partial response (residual symptoms at effective doses of oral antipsychotic) and 1 point for lack of response and need for clozapine.

\section{Family support}

Family support is important as the other elements of therapeutic management [21]. In patients with adherence problems, the lack of family members involved in the therapeutic process is considered a predictor of therapeutic abandonment, even when initiating depot formulas.

The presence of 2 or more family members close to the patient was rated with 5 points, of a single member with 3 points and in situations where the patient is alone only 1 point.

\section{Vl. Antipsychotic existing formulation}

If the patient received an OAP that also has LAl formulation (aripiprazole, olanzapine, risperidone, and paliperidone) we gave 5 points, if there is only the oral formulation (amisulpride and quetiapine) we gave 3 points and if the patient was on clozapine 1 point.

\section{Treatment adherence}

Assessing adherence to treatment is a complex and subjective approach. Many methods have been proposed, none of which are perfect. In general, the patient with schizophrenia can be considered as adherent, partially adherent or non-adherent $[22,23]$. In the patient's file, on admission, it is mentioned if the patient is adherent, partially adherent or non-adherent. The adherence was evaluated using Kemp's 7point scale [24]. For the 3 variants listed, we rated 1 point for good adherence, 3 points for partial adherence and 5 points for poor adherence.

\subsection{Scoring, interpretation and recommendations}

All 7 items of the index have equal importance in the management of the patient with schizophrenia when LAl initiation has taken into account. The final score obtained could range from minimum of 7 points to a maximum of 35 points, placing the patient in one of the following categories:

25-35 points = strong indication for LAl initiation. This score indicates the need for a preventive action. It means that the patient has the premises (age, duration of the disease, support, therapeutic response) and the highest chances of total functional recovery. LAI should be initiated as soon as possible to prevent a new relapse or hospitalization.

15-23 points $=$ moderate indication for LAl initiation. This score indicates the need for a better functionality action. It should be interpreted as a score in which the patient can benefit from LAI for 
significant improvement in functioning and therefore a better social and professional integration.

07-13 points = low indication for LAl initiation. This score indicates the need for a better autonomy action. It means that long-acting treatment could increase patient' autonomy especially in the cases of patients with low support, low income or homeless.

The initiation index must be interpreted with few recommendations. In the case of patients with no relapse, there is still the possibility of therapeutic abandonment, so initiation is a preventive measure. In treatment-resistant schizophrenia, we have to decide if it is really a case of resistance or is in fact nonadherence. In the case of false treatment resistance situation, we recommend LAI initiation.

For patients on clozapine for treatment-resistance or for aggressive behavior switching to an LAl is not recommended. In cases of severe adverse events this switch must be done very carefully.

\section{Methods}

\subsection{Setting, study design and measures}

To assess the LAI initiation, we conducted a retrospective study in the Clinical Hospital of Psychiatry and Neurology in Brasov, an academic setting with 120 beds for acute patients. The inclusion criteria were the diagnosis of schizophrenia according to Diagnostic and Statistical Manual of Mental Disorders, Fifth Edition (DSM-5), aged 18-45 years, and no history of LAl treatment. The period was between 1 January 2010 and 31 December 2019.

The data included the age of onset of the disease, the duration of the disease, the number of relapses, the response to antipsychotic treatment, adherence to treatment, the number of family members with whom the patient lives and the available formulas of the antipsychotic with which the patient was discharged.

Clinical interviews, health and psychiatric records and chart reviews were used to collect participants 'data. The scale used in this research were to assess adherence was Kemp's 7-point scale.

The study was approved by the local ethics committee.

\subsection{Statistical analysis}

For statistical analysis of the data, we used the Statistical Package for Social Sciences (SPSS Inc., Chicago, Illinois, USA) software for Windows (version 21). Demographic, clinical, and treatment variables were compared using Chi Square Tests (categorical variables) or ANOVAs (continuous variables). All statistics were two-tailed.

\section{Results}

During the 10-year research period, 1116 different patients with schizophrenia were hospitalized. Of these, 477 (42.7\%) met the age eligibility criteria (between 18 and 45 years). A total of 225 patients out of 
$477(47.1 \%)$ with the mean age of 37.8 years $(S D \pm 5.9)$ had never had treatment with LAls lifetime. Patients' characteristics are presented in Table 2. 
Table 2

Demographics

\begin{tabular}{|c|c|}
\hline \multicolumn{2}{|l|}{ Parameters } \\
\hline Male gender $(n ; \%)$ & $52 ; 53.6 \%$ \\
\hline Age (mean, SD) & $36.7 ; \pm 5.6$ \\
\hline \multicolumn{2}{|l|}{ Age group } \\
\hline$-18-25$ years $(n ; \%)$ & $1 ; 0.9 \%$ \\
\hline$-26-35$ years $(n ; \%)$ & $30 ; 30.9 \%$ \\
\hline$-36-45$ years $(n ; \%)$ & $66 ; 68.2 \%$ \\
\hline Duration of illness (mean, SD) & $12.4 ; \pm 14.1$ \\
\hline \multicolumn{2}{|l|}{ Duration of illness group } \\
\hline$-2-5$ years $(n ; \%)$ & $22 ; 22.7 \%$ \\
\hline$-6-10$ years $(n ; \%)$ & $18 ; 18.6 \%$ \\
\hline - > 10 years $(\mathbf{n} ; \%)$ & $57 ; 58.7 \%$ \\
\hline \multicolumn{2}{|l|}{ Relapses } \\
\hline - 2 or more 2 relapses $(\mathbf{n} ; \%)$ & $88 ; 90.7 \%$ \\
\hline - 1 relapse $(n ; \%)$ & $5 ; 5.2 \%$ \\
\hline - No relapse (n; \%) & $4 ; 4.1 \%$ \\
\hline \multicolumn{2}{|l|}{ Family support } \\
\hline - 2 members or more $(\mathbf{n} ; \%)$ & $36 ; 37.1 \%$ \\
\hline - 1 member (n; \%) & $40 ; 41.2 \%$ \\
\hline - No member (n; \%) & $21 ; 21.7 \%$ \\
\hline \multicolumn{2}{|l|}{ Response to oral AP } \\
\hline - Good response (n; \%) & $56 ; 57.7 \%$ \\
\hline - Partial response (n; \%) & $40 ; 41.3 \%$ \\
\hline - No response $(\mathbf{n} ; \%)$ & $1 ; 1 \%$ \\
\hline \multicolumn{2}{|l|}{ Adherence } \\
\hline - Good (n, \%) & $13 ; 13.4 \%$ \\
\hline - Partial (n, \%) & $9 ; 9.3 \%$ \\
\hline
\end{tabular}




\begin{tabular}{|ll|}
\hline Parameters \\
\hline - Non-adherence $(\mathbf{n}, \%)$ & $75 ; 77.3 \%$ \\
\hline No of antipsychotics used life time & \\
\hline-1 or $2(\mathbf{n} ; \%)$ & $35 ; 36.1 \%$ \\
\hline-3 or $4(\mathbf{n} ; \%)$ & $41 ; 42.2 \%$ \\
\hline-5 or more $(\mathbf{n} ; \%)$ & $22 ; 22.7 \%$ \\
\hline
\end{tabular}

Using the index, we can get 15 score variants, between 7 and 35 , only odd scores and different number of potential SLAll variants (Table3).

Table 3

Distribution of SLAll score

\begin{tabular}{|llllllllllllllll|}
\hline $\begin{array}{l}\text { SLAll score } \\
\text { variants }\end{array}$ & $\mathbf{7}$ & $\mathbf{9}$ & $\mathbf{1 1}$ & $\mathbf{1 3}$ & $\mathbf{1 5}$ & $\mathbf{1 7}$ & $\mathbf{1 9}$ & $\mathbf{2 1}$ & $\mathbf{2 3}$ & $\mathbf{2 5}$ & $\mathbf{2 7}$ & $\mathbf{2 9}$ & $\mathbf{3 1}$ & $\mathbf{3 3}$ & $\mathbf{3 5}$ \\
\hline $\begin{array}{l}\text { Number of the } \\
\text { potential } \\
\text { variants }\end{array}$ & 1 & 1 & 2 & 2 & 3 & 3 & 4 & 4 & 5 & 3 & 3 & 2 & 1 & 1 & 1 \\
\hline
\end{tabular}

The scores obtained by the patients are presented in Fig. 1.

Most patients were young, 57 patients (25.3\%) aged in the critical period of the disease (3rd decade of life, between 20 and 30 years) [25]. A significant number of patients in this age group had a maximum score at least 4 items indicating the need for LAl initiation. 203 patients $(90.2 \%)$ had more than 2 relapses. 105 patients ( $46.7 \%$ ) lived with at least one family member. $68 \%$ of patients was non-adherent which confirms that $2 / 3$ of patients with schizophrenia are not treatment compliant (Table 4).

Table 4

The index items

\begin{tabular}{|llll|}
\hline Items & \multicolumn{3}{l}{ Score } \\
\cline { 2 - 4 } & $\mathbf{5}$ points & $\mathbf{3}$ points & $\mathbf{1}$ point \\
\hline age (n; years; \%) & $20 ; 8.9 \%$ & $71 ; 31.5 \%$ & $134 ; 59.6 \%$ \\
\hline duration of illness (n; years; \%) & $35 ; 15.6 \%$ & $84 ; 37.3 \%$ & $106 ; 47.1 \%$ \\
\hline relapses (n; \%) & $203 ; 90.2 \%$ & $12 ; 5.3 \%$ & $10 ; 4.5 \%$ \\
\hline response to OAPs (n; \%) & $140 ; 62.2 \%$ & $78 ; 34.7 \%$ & $7 ; 3.1 \%$ \\
\hline family support $(n ; \%)$ & $84 ; 37.3 \%$ & $105 ; 46.7 \%$ & $36 ; 16 \%$ \\
\hline AP formulation $(n ; \%)$ & $177 ; 78.7 \%$ & $43 ; 19.1 \%$ & $5 ; 2.2 \%$ \\
\hline adherence $(n ; \%)$ & $154 ; 68.4 \%$ & $55 ; 24.5 \%$ & $16 ; 7.1 \%$ \\
\hline
\end{tabular}


The results of our research showed that 177 patients $(78.7 \%)$ received at discharge an OAP that also had a long-acting formula. A well-known fact in Romania is the affinity of clinicians for olanzapine, an antipsychotic described as being efficient, cheap, affordable even for the uninsured patients, largely available and having a long-acting formulation. Olanzapine long-acting formula has the disadvantage of requiring post-injection monitoring for a period of 3 hours, which makes it difficult to initiate, (fact obvious in the current COVID-19 pandemic) [26]. The antipsychotic used at discharge are presented in Table 5.

Table 5

Antipsychotic used at discharge

\begin{tabular}{|c|c|c|c|c|c|c|c|c|}
\hline \multicolumn{3}{|c|}{ Oral antipsychotics } & \multicolumn{6}{|c|}{ Concomitant medication } \\
\hline OAPs & $\mathrm{n} ; \%$ & $\begin{array}{l}\text { Dose (mean, } \\
\text { SD) }\end{array}$ & $\begin{array}{l}\text { MS }(n ; \\
\%)\end{array}$ & $\begin{array}{l}\text { BZD }(n ; \\
\%)\end{array}$ & $\begin{array}{l}\text { ACh }(n ; \\
\%)\end{array}$ & $\begin{array}{l}\operatorname{HYP}(n ; \\
\%)\end{array}$ & $\begin{array}{l}A D \\
(n \%)\end{array}$ & $\begin{array}{l}\text { 2ndAP (n; } \\
\text { \%) }\end{array}$ \\
\hline OLZ & $\begin{array}{l}124 ; \\
55.1 \%\end{array}$ & $\begin{array}{l}15.3 \mathrm{mg} \text { × } \\
4.7\end{array}$ & $\begin{array}{l}102 ; \\
45.3 \%\end{array}$ & $\begin{array}{l}116 ; \\
51.5 \%\end{array}$ & $\begin{array}{l}28 ; \\
12.4 \%\end{array}$ & $\begin{array}{l}20 ; \\
20.9 \%\end{array}$ & $\begin{array}{l}4 ; \\
1.7 \%\end{array}$ & $23 ; 10.2 \%$ \\
\hline QUE & $\begin{array}{l}25 ; \\
11.1 \%\end{array}$ & $\begin{array}{l}550 \mathrm{mg} ; \pm \\
151\end{array}$ & $17 ; 68 \%$ & $15 ; 60 \%$ & $6 ; 24 \%$ & - & - & $3 ; 12 \%$ \\
\hline CLO & $5 ; 2.2 \%$ & $\begin{array}{l}300 \mathrm{mg} \pm \\
112\end{array}$ & - & - & - & - & - & - \\
\hline RIS & $\begin{array}{l}28 \\
12.4 \%\end{array}$ & $\begin{array}{l}3.2 \mathrm{mg} ; \pm \\
0.91\end{array}$ & $\begin{array}{l}8 ; \\
28.6 \%\end{array}$ & $\begin{array}{l}15 \\
53.6 \%\end{array}$ & $\begin{array}{l}12 ; \\
42.9 \%\end{array}$ & $\begin{array}{l}6 ; \\
21.4 \%\end{array}$ & $2 ;$ & - \\
\hline PAL & $\begin{array}{l}11 ; \\
4.9 \%\end{array}$ & $\begin{array}{l}7.5 \mathrm{mg} ; \pm \\
1.73\end{array}$ & $\begin{array}{l}4 ; \\
36.4 \%\end{array}$ & $\begin{array}{l}5 ; \\
45.5 \%\end{array}$ & - & $\begin{array}{l}3 ; \\
27.3 \%\end{array}$ & - & - \\
\hline AMI & $\begin{array}{l}13 ; \\
5.8 \%\end{array}$ & $\begin{array}{l}514 \mathrm{mg} ; \pm \\
195\end{array}$ & $\begin{array}{l}4 ; \\
30.7 \%\end{array}$ & $\begin{array}{l}6 ; \\
46.1 \%\end{array}$ & $1 ; 7.7 \%$ & $\begin{array}{l}2 ; \\
15.4 \%\end{array}$ & - & - \\
\hline ARI & $9 ; 4 \%$ & $18 \mathrm{mg} ; \pm 8.3$ & $\begin{array}{l}4 ; \\
44.4 \%\end{array}$ & $\begin{array}{l}3 ; \\
33.3 \%\end{array}$ & - & $\begin{array}{l}3 ; \\
33.3 \%\end{array}$ & - & - \\
\hline HAL & $\begin{array}{l}10 ; \\
4.4 \%\end{array}$ & $7,7 \mathrm{mg} ; \pm 2.9$ & $6 ; 60 \%$ & $8 ; 80 \%$ & $5 ; 50 \%$ & - & - & - \\
\hline $\begin{array}{l}\text { (OAPS } \\
\text { PAL = } \\
\text { BZD = } \\
\text { conco }\end{array}$ & $\begin{array}{l}\text { al an } \\
\text { eridc } \\
\text { zodia } \\
\text { nt us }\end{array}$ & $\begin{array}{l}\text { hotics; OLZ } \\
\text { MI = amisul } \\
\text { e; ACh = ant } \\
\text { 2nd antips }\end{array}$ & $\begin{array}{l}\text { anzapir } \\
\text { iRI } \\
\text { inergic } \\
\text { tic) }\end{array}$ & $\begin{array}{l}\mathrm{JE}=\text { que } \\
\text { razole; } \\
=\text { hypn }\end{array}$ & $\begin{array}{l}\text { ine; } C L \\
=\text { halc } \\
; A D=\end{array}$ & $\begin{array}{l}\text { clozapi } \\
\text { dol; Ms } \\
\text { epress }\end{array}$ & $\begin{array}{l}\text { IS }=r i \\
\text { lood } s \\
\text { 2nd A }\end{array}$ & $\begin{array}{l}\text { eridone; } \\
\text { ilizer; }\end{array}$ \\
\hline
\end{tabular}

Evaluation of patients with SLAll showed that 144 patients (64\%) had a strong indication for initiating LAI and $36(37.1 \%)$ had moderate indication. Five patients, discharged on clozapine, without previous longacting treatment, was considered as having a low indication (Fig. 2).

\section{Discussion}


We have described the development and initial standardization of the 7- item SLAll as an instrument for measuring the need for LAl initiation in schizophrenia.

As far as we know, this is the first index created to encourage the initiation of LAl in schizophrenia, providing evidence to not delay this treatment.

Although many studies indicate that the use of LAls may have the potential to prevent relapses and hospitalization compared with oral antipsychotic use [27], and although second-generation LAI formulations are widely available, it has been estimated that only $10-20 \%$ of eligible patients are actually prescribed LAls [28]. The results obtained show that a significant number of patients who had an indication for LAI was discharged with OAPs.

One explanation for why these agents are under-initiated may be the current lack of clear and practical guidelines on how and to whom to initiate treatment with these agents. Studies show that initiation is common in severe patients, with involuntary hospitalizations, with evidence of non-adherence to treatment [29]. This could lead to a decline in LAl confidence.

Despite availability of all LAls formulation in Romania, free of charge for insured patients with schizophrenia, a significant percentage of patients with a strong indication for LAls (64\%) were still discharged on OAP.

We must emphasize that the presence of a low score should not be a barrier in initiating LAI. The initiation of LAl in these patients if it is followed by all measures to ensure adherence (government programs, institutional support, etc.) can lead to reduced hospitalizations, direct and indirect costs and an acceptable degree of patient autonomy.

This index can also enhance the patient's collaboration and the family support of the treatment management because presenting the need for initiation score could build a strong confidence in the clinician's judgment.

With minimal time investment, patients and their families could become sufficiently informed to accept LAl initiation. It could also help psychiatrists working only in the outpatient department or in private practice to initiate LAl because this type of treatment is usually initiated in the hospital.

Like any instrument, the SLAll scale has several limitations. One limitation could be the application of this index to patients with concomitant medication which could rise or low the serum level of antipsychotic [30]. Another limitation would be the application of the LAl initiation index to young patients who are pregnant where initiation still raises widespread debate [31]. The present study design did not specifically address effectiveness of a proposed index. We report evaluation on the relatively small number of patients and preliminary experience with this index have been encouraging.

Should the validity of the SLAll be upheld by future studies and independent investigators, its use might be expected to promote uniformity and reliability in research findings. 


\section{Conclusion}

This paper describes an index designed to improve treatment outcomes in schizophrenia and can be implemented in routine clinical management. SLAll has potential value in a wide range of settings. It can be used by clinicians in hospitals to argue the therapeutic decision, or in the outpatient department when evidence of non-adherence appears.

\section{Abbreviations}

LAls: Long-acting injectable antipsychotics; SLAll: Schizophrenia long-acting antipsychotic initiation index; DSM-5: Diagnostic and Statistical Manual of Mental Disorders, Fifth Edition; OAP: Oral antipsychotic

\section{Declarations}

\section{Acknowledgements}

We would like to thank all participants who shared their time and the organizations for their help in data collection.

\section{Availability of data and materials}

Data is available from the corresponding author upon reasonable request.

\section{Declarations}

\section{Ethics approval, guidelines and consent to participate}

All participants provided written informed consent. This study was approved by the Ethics Committee of Hospital of Psychiatry and Neurology of Brasov, Romania. All methods were performed in accordance with the relevant guidelines and regulations.

\section{Consent for publication}

NA.

\section{Competing interests}

There is no conflict of interest for all authors.

\section{Availability of data and materials}

Data is available from the corresponding author upon reasonable request.

\section{Funding}


No funding.

\section{Authors' contributions}

IP and TA collected data, revised this manuscript; IP wrote this paper. All authors approved the publication of this manuscript.

\section{References}

1. Kahn RS, Sommer IE, Murray RM, Meyer-Lindenberg A, Weinberger DR, Cannon TD, O'Donovan M, Correll CU, Kane JM, van Os J, Insel TR. Schizophrenia. Nat Rev Dis Primers. 2015 Nov 12;1:15067. doi: 10.1038/nrdp.2015.67.

2. Świtaj P, Anczewska M, Chrostek A, Sabariego C, Cieza A, Bickenbach J, Chatterji S. Disability and schizophrenia: a systematic review of experienced psychosocial difficulties. BMC Psychiatry. 2012 Nov 9;12:193. doi: 10.1186/1471-244X-12-193.

3. Lysaker PH, Pattison ML, Leonhardt BL, Phelps S, Vohs JL. Insight in schizophrenia spectrum disorders: relationship with behavior, mood and perceived quality of life, underlying causes and emerging treatments. World Psychiatry. 2018 Feb;17(1):12-23. doi: 10.1002/wps.20508.

4. Shafrin J, Silverstein AR, MacEwan JP, Lakdawalla DN, Hatch A, Forma FM. Using Information on Patient Adherence to Antipsychotic Medication to Understand Their Adherence to Other Medications. P T. 2019 Jun;44(6):350-357.

5. Johnson S, Sathyaseelan M, Charles H, Jeyaseelan V, Jacob KS. Insight, psychopathology, explanatory models and outcome of schizophrenia in India: a prospective 5-year cohort study. BMC Psychiatry. 2012 Sep 27;12:159. doi: 10.1186/1471-244X-12-159.

6. Taipale H, Mittendorfer-Rutz E, Alexanderson K, Majak M, Mehtälä J, Hoti F, Jedenius E, Enkusson D, Leval A, Sermon J, Tanskanen A, Tiihonen J. Antipsychotics and mortality in a nationwide cohort of 29,823 patients with schizophrenia. Schizophr Res. 2018 Jul;197:274-280. doi: 10.1016/j.schres.2017.12.010.

7. Nasrallah HA. Triple advantages of injectable long acting second generation antipsychotics: Relapse prevention, neuroprotection, and lower mortality. Schizophr Res. 2018 Jul;197:69-70. doi: 10.1016/j.schres.2018.02.004.

8. Taylor DM, Velaga S, Werneke U. Reducing the stigma of long acting injectable antipsychotics current concepts and future developments. Nord J Psychiatry. 2018 Sep;72(sup1):S36-S39. doi: 10.1080/08039488.2018.1525638.

9. Law MR, Soumerai SB, Ross-Degnan D, Adams AS. A longitudinal study of medication nonadherence and hospitalization risk in schizophrenia. J Clin Psychiatry. 2008 Jan;69(1):47-53. doi: 10.4088/jcp.v69n0107.

10. Sajatovic M, Ross R, Legacy SN, Byerly M, Kane JM, DiBiasi F, Fitzgerald H, Correll CU. Initiating/maintaining long-acting injectable antipsychotics in schizophrenia/schizoaffective or 
bipolar disorder - expert consensus survey part 2. Neuropsychiatr Dis Treat. 2018 Jun 8;14:14751492. doi: $10.2147 /$ NDT.S167485.

11. Kishimoto T, Sanghani S, Russ MJ, Marsh AN, Morris J, Basu S, John M, Kane JM. Indications for and use of long-acting injectable antipsychotics: consideration from an inpatient setting. Int Clin Psychopharmacol. 2017 May;32(3):161-168. doi: 10.1097/YIC.0000000000000165.

12. Marcus SC, Zummo J, Pettit AR, Stoddard J, Doshi JA. Antipsychotic Adherence and Rehospitalization in Schizophrenia Patients Receiving Oral Versus Long-Acting Injectable Antipsychotics Following Hospital Discharge. J Manag Care Spec Pharm. 2015 Sep;21(9):754-68. doi: 10.18553/jmcp.2015.21.9.754.

13. Citrome L. Long-acting injectable antipsychotics: what, when, and how. CNS Spectr. 2021 Mar 15:112. doi: $10.1017 /$ S1092852921000249.

14. Correll CU, Lauriello J. Long-Acting Injectable Antipsychotics: Where Do They Fit in the Treatment Plan? J Clin Psychiatry. 2018 Jan/Feb;79(1):AL17017WC1C. doi: 10.4088/JCP.AL17017WC1C.

15. Albert N, Bertelsen M, Thorup A, Petersen L, Jeppesen P, Le Quack P, Krarup G, Jørgensen P, Nordentoft M. Predictors of recovery from psychosis Analyses of clinical and social factors associated with recovery among patients with first-episode psychosis after 5 years. Schizophr Res. 2011 Feb;125 (2-3):257-66. doi: 10.1016/j.schres.2010.10.013.

16. Kane JM, Schooler NR, Marcy P, Correll CU, Achtyes ED, Gibbons RD, Robinson DG. Effect of LongActing Injectable Antipsychotics vs Usual Care on Time to First Hospitalization in Early-Phase Schizophrenia: A Randomized Clinical Trial. JAMA Psychiatry. 2020 Jul 15;77(12):1-8. doi: 10.1001/jamapsychiatry.2020.2076.

17. Chi MH, Hsiao CY, Chen KC, Lee LT, Tsai HC, Hui Lee I, Chen PS, Yang YK. The readmission rate and medical cost of patients with schizophrenia after first hospitalization - A 10-year follow-up population-based study. Schizophr Res. 2016 Jan;170(1):184-90. doi: 10.1016/j.schres.2015.11.025.

18. Tiihonen J, Taipale H, Mehtälä J, Vattulainen P, Correll CU, Tanskanen A. Association of Antipsychotic Polypharmacy vs Monotherapy With Psychiatric Rehospitalization Among Adults With Schizophrenia. JAMA Psychiatry. 2019 May 1;76(5):499-507. doi: 10.1001/jamapsychiatry.2018.4320.

19. Ventura J, Subotnik KL, Guzik LH, Hellemann GS, Gitlin MJ, Wood RC, Nuechterlein KH. Remission and recovery during the first outpatient year of the early course of schizophrenia. Schizophr Res. 2011 Oct;132(1):18-23. doi: 10.1016/j.schres.2011.06.025.

20. Takeuchi H, Siu C, Remington G, Fervaha G, Zipursky RB, Foussias G, Agid O. Does relapse contribute to treatment resistance? Antipsychotic response in first- vs. second-episode schizophrenia. Neuropsychopharmacology. 2019 May;44(6):1036-1042. doi: 10.1038/s41386-018-0278-3.

21. McFarlane WR. Family Interventions for Schizophrenia and the Psychoses: A Review. Fam Process. 2016 Sep;55(3):460-82. doi: 10.1111/famp.12235. 
22. Kane JM, Correll CU. Optimizing Treatment Choices to Improve Adherence and Outcomes in Schizophrenia. J Clin Psychiatry. 2019 Sep 17;80(5):IN18031AH1C. doi: 10.4088/JCP.IN18031AH1C.

23. Smith RL, Tveito M, Kylles $\varnothing$ L, Jukic MM, Ingelman-Sundberg M, Andreassen OA, Molden E. Rates of complete nonadherence among atypical antipsychotic drugs: A study using blood samples from 13,217 outpatients with psychotic disorders. Schizophr Res. 2021 Feb;228:590-596. doi: 10.1016/j.schres.2020.11.025.

24. Kemp R, Hayward P, Applewhaite G, Everitt B, David A. Compliance therapy in psychotic patients: randomised controlled trial. BMJ. 1996 Feb 10;312(7027):345-9. doi: 10.1136/bmj.312.7027.345.

25. Lieberman JA, Perkins D, Belger A, Chakos M, Jarskog F, Boteva K, Gilmore J. The early stages of schizophrenia: speculations on pathogenesis, pathophysiology, and therapeutic approaches. Biol Psychiatry. 2001 Dec 1;50(11):884 - 97. doi: 10.1016/s0006-3223(01)01303-8.

26. Ifteni P, Dima L, Teodorescu A. Long-acting injectable antipsychotics treatment during COVID-19 pandemic - A new challenge. Schizophr Res. 2020 Jun;220:265-266. doi:

10.1016/j.schres.2020.04.030.

27. Kishimoto T, Nitta M, Borenstein M, Kane JM, Correll CU. Long-acting injectable versus oral antipsychotics in schizophrenia: a systematic review and meta-analysis of mirror-image studies. $J$ Clin Psychiatry. 2013 Oct;74(10):957-65. doi: 10.4088/JCP.13r08440.

28. Patel MX, Bent-Ennakhil N, Sapin C, di Nicola S, Loze JY, Nylander AG, Heres S. Attitudes of European physicians towards the use of long-acting injectable antipsychotics. BMC Psychiatry. $2020 \mathrm{Mar}$ 14;20(1):123. doi: 10.1186/s12888-020-02530-2.

29. Lin CH, Chen FC, Chan HY, Hsu CC. Time to Rehospitalization in Patients With Schizophrenia Receiving Long-Acting Injectable Antipsychotics or Oral Antipsychotics. Int J Neuropsychopharmacol. 2019;22(9):541-547. doi:10.1093/ijnp/pyz035.

30. Jönsson AK, Spigset O, Reis M. A Compilation of Serum Concentrations of 12 Antipsychotic Drugs in a Therapeutic Drug Monitoring Setting. Ther Drug Monit. 2019 Jun;41(3):348-356. doi: 10.1097/FTD.0000000000000585.

31. Teodorescu A, Ifteni P, Moga MA, Burtea V, Bigiu N. Dilemma of treating schizophrenia during pregnancy: a Case series and a review of literature. BMC Psychiatry. 2017 Aug 29;17(1):311. doi: 10.1186/s12888-017-1475-z.

\section{Figures}




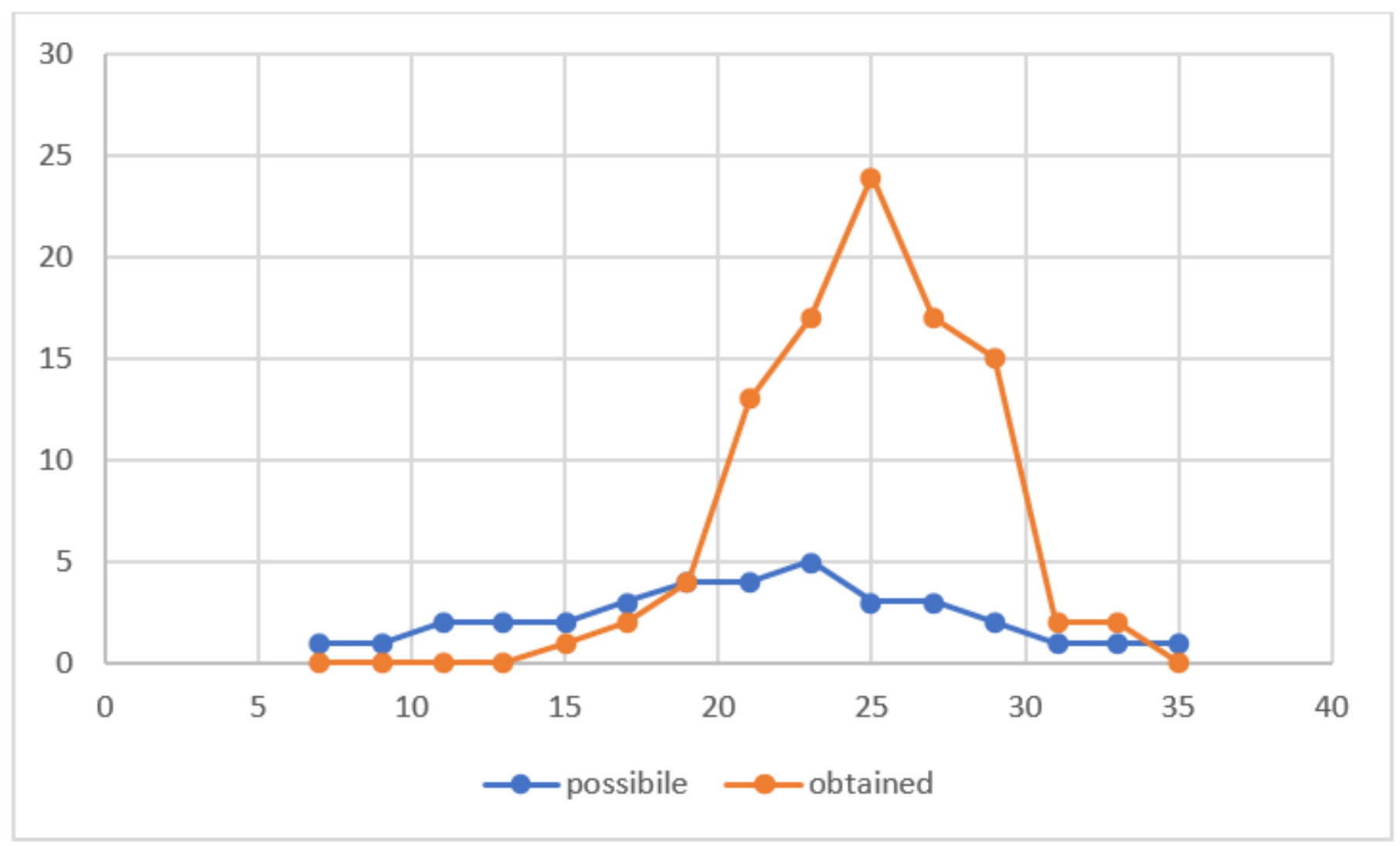

Figure 1

Distribution of possible scores and those obtained using SLAll. 


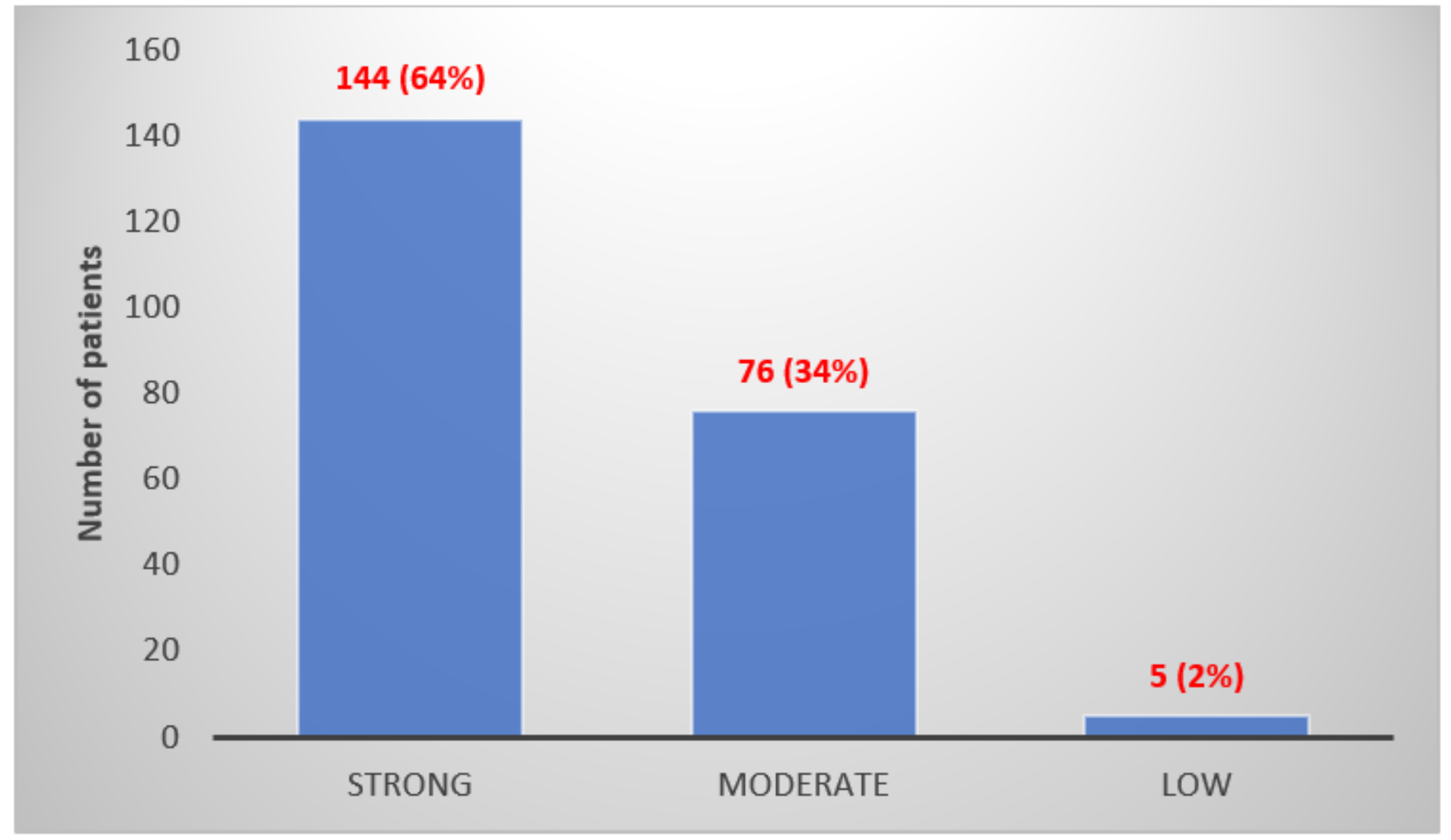

Figure 2

Indication for LAl initiation (strong, moderate, and low). 